\title{
FGF4 induces epithelial-mesenchymal transition by inducing store-operated calcium entry in lung adenocarcinoma
}

\author{
Lisha Qi ${ }^{1,5,6}$, Wangzhao Song ${ }^{1,4,5,6}$, Lingmei $\mathbf{L i}^{1,5,6}$, Lu Cao ${ }^{1,4,5,6}$, Yue Yu ${ }^{2,5,6}$, Chunmin \\ Song $^{8}$, Yalei Wang ${ }^{1,5,6}$, Fei Zhang ${ }^{5,6,7}$, Yang Li ${ }^{3,4,5,6}$, Bin Zhang ${ }^{2,5,6}$, Wenfeng Cao ${ }^{1,5,6}$ \\ ${ }^{1}$ Department of Pathology, Tianjin Medical University Cancer Institute and Hospital, Tianjin 300060, China \\ ${ }^{2}$ Department of Breast Cancer, Tianjin Medical University Cancer Institute and Hospital, Tianjin 300060, China \\ ${ }^{3}$ Department of Pancreatic Cancer, Tianjin Medical University Cancer Institute and Hospital, Tianjin 300060, China \\ ${ }^{4}$ Tianjin Medical University, Tianjin 300070, China \\ ${ }^{5}$ The Key Laboratory of Tianjin Cancer Prevention and Treatment, Tianjin 300060, China \\ ${ }^{6}$ National Clinical Research Center for Cancer, Tianjin 300060, China \\ ${ }^{7}$ Research Center of Basic Medical Sciences, Tianjin Medical University Cancer Institute and Hospital, Tianjin 300060, China \\ ${ }^{8}$ Department of Family Planning, Maternity \& Child Care Center of Luoyang, Luoyang 471000, China \\ Correspondence to: Bin Zhang, email: eeflying@163.com \\ Wenfeng Cao, email: caowenfeng@tjmuch.com \\ Keywords: FGF4, epithelial-mesenchymal transition, store-operated calcium entry, Orai 1, FGF7
}

Received: February 04, $2016 \quad$ Accepted: August 23, $2016 \quad$ Published: September 22, 2016

\section{ABSTRACT}

Several fibroblast growth factor (FGF) isoforms act to stimulate epithelialmesenchymal transition (EMT) during cancer progression. FGF4 and FGF7 are two ligands of FGF receptor 2 (FGFR2). Using two lung adenocarcinoma (ADC) cell lines, A549 and H1299, we showed that FGF4, but not FGF7, altered cell morphology, promoted EMT-associated protein expression, and enhanced cell proliferation, migration/invasion and colony initiation. In addition, FGF4 increased store-operated calcium entry (SOCE) and expression of the calcium signal-associated protein Orai1. The SOCE inhibitor 2,5-di-tert-butylhydroquinone (BHQ) or Orai1 knockdown reversed all of the EMT-promoting effects of FGF4. BHQ also inhibited FGF4-induced EMT in a mouse xenograft model. Finally, 60 human lung ADC samples and 21 sets of matched specimens (primary and metastatic foci in lymph nodes from one patient) were used to confirm the clinicopathologic significance of FGF4 and its correlation with E-cadherin, Vimentin and Orai 1 expression. Our study thus shows that FGF4 induces EMT by elevating SOCE in lung ADC.

\section{INTRODUCTION}

The fibroblast growth factor (FGF) family consists of at least 23 members. FGFs are involved in numerous physiological processes, ranging from vertebrate segmentation and elongation of the embryonic axis to skeletal development $[1,2]$. FGF overexpression has been linked with the pathogenesis and progression of multiple cancers, including breast, prostate [3] and lung cancer [4].

Epithelial-mesenchymal transition (EMT) is a crucial process in cancer progression. During EMT, epithelial cells escape from their origin, gain fibroblastic characteristics, and migrate to distant locations $[5,6]$. The EMT program is promoted by many soluble growth factors, including FGFs [2, 7]. For example, the activation of the FGFR/MEK/ERK pathway by FGF2 promotes cell growth and EMT in the chordoma [8] and FGF10 can induce EMT of breast cancer cells [9]. Furthermore, FGF8 can induce a more aggressive phenotype displaying EMT and enhanced invasion and growth in colorectal cancer cells [10]. Takanami et al. measured FGF2 expression in 143 lung adenocarcinoma (ADC) tissues [11] and found that high FGF2 expression was a prognostic indicator for unfavorable outcome. Donnem and colleagues showed that high FGF2 expression in non-small-cell lung cancer (NSCLC) is associated with poor five-year survival [4]. Li demonstrated that immunoreactive scores of FGF1 were higher in NSCLC specimens than in peritumoral normal tissues and patients with high FGF1 expression had a lower overall survival rate [12]. NSCLC patients with 
high FGF9 expression were also reported to have a worse prognosis than those with low FGF9 expression [13].

FGF signals are transduced through FGF receptors (FGFRs). Alternative splicing of FGFR2 mRNA generates the FGFR2-IIIb isoform, which selectively binds FGF7 with high affinity, or the FGFR2-IIIc isoform, which selectively binds FGF4. The dedicated ligands for FGFR2-IIIb and FGFR2-IIIc are usually expressed in mesenchymal and epithelial cells, respectively $[2,14$, 15]. A switch from FGFR2-IIIb to FGFR2-IIIc has been reported in the malignant progression of prostate and bladder cancer $[14,16]$. In our study, out of the 23 reported FGFs, we focused on FGF4 and FGF7, the representative FGF ligands for FGFR2 splice variants, and studied their functions in the EMT program of lung ADC.

EMT has been linked with the dysregulation of FGF/ FGFR signaling, including MEK/ERK and PI3K-AKT signaling $[2,8,17]$. In addition, the activation of FGF/ FGFR can activate inositol trisphosphate (IP3), which triggers $\mathrm{Ca}^{2+}$ signaling [18]. As a ubiquitous secondary messenger, intracellular calcium regulates nearly every aspect of cellular function, including excitability, exocytosis, cytoskeletal reorganization, motility, deformability, and gene expression [19]. Altered $\mathrm{Ca}^{2+}$ homeostasis is also a hallmark of numerous cancers, including breast, prostate, and ovarian cancers [6, 20-23]. Store-operated calcium entry (SOCE) is responsible for activating $\mathrm{Ca}^{2+}$ channels in the plasma membrane following depletion of $\mathrm{Ca}^{2+}$ stores. SOCE is the foremost pattern for ectocytic $\mathrm{Ca}^{2+}$ entry in non-excitable epithelial cells [19, 24, 25]. The molecular components of SOCE include the endoplasmic reticulum $\mathrm{Ca}^{2+}$ sensors stromal interaction molecule1 (STIM1), STIM2 and the store-operated $\mathrm{Ca}^{2+}$ channel-forming subunits Orai1, Orai2, and Orai3. Orai1 is recognized as the central component of SOCE because of it exhibits the highest potency in the conduction of $\mathrm{Ca}^{2+}$ currents $[25,26]$. Although several studies reported that altered SOCE is linked to EGF [22] and TGF-induced EMT [27], the effects of SOCE induced by FGF in EMT remain unclear.

In the present study, we show that FGF4, but not FGF7, induces EMT and promotes proliferation, migration/invasion, and colony initiation in A549 and H1299 lung ADC cell lines. More importantly, we demonstrate that FGF4 induces EMT via enhancement of SOCE in lung ADC.

\section{RESULTS}

\section{Treatment with FGF4, but not FGF7, induces EMT, causes a switch from FGFR2 IIIb to FGFR2 IIIC and changes the morphology and behavior of A549 and H1299 cells}

To evaluate the effect of FGF4 and FGF7 on promoting EMT, A549 and H1299 cells were treated at different concentrations of $0,5,10,25$, and $50 \mathrm{ng} / \mathrm{mL}$ for
24 h. As shown in Figure 1A, FGF4 decreased E-cadherin and increased Vimentin expression in both cell lines. In addition to the classical EMT markers, we also checked the expression of an array of EMT transcription factors, including Snail, Slug, and Twist. These factors could induce EMT by directly binding to the E-boxes of the E-cadherin promoter. Among these three factors, Snail and Twist were upregulated in the cells exposed to FGF4. Moreover, the EMT-promoting effect of FGF4 on both cells was dose-dependent. In contrast to FGF4, FGF7 showed no evident influence on the expression of these EMT-associated proteins.

Except for alterations in epithelial and mesenchymal proteins expression, we also found alterations in cellular morphology and functional phenotypes. By using phalloidin to dye fibrous actin (F-actin), we observed that FGF4 treatment (10 ng/m, $24 \mathrm{~h}$ ) caused A549 and H1299 cells to form structures with irregular shape and non-uniform composition (Figure 1C). In CCK8 assays, we observed that FGF4 could promote cell proliferation as early as the third day (Figure 1D). In migration and invasion assays, significantly more cells passed through the transwell chamber filter when stimulated with FGF4, compared with control cells (Figure 1E). Anchorage-independent growth was increased in cells with FGF4 stimulation (Figure 1F). Compared with control cells, FGF7 showed no influence on proliferation, migration/invasion, and colony-initiating ability of A549 and H1299 cells.

\section{FGF4 elevates intracellular calcium concentration and increases the expression of Orai1}

Binding of some FGF ligands to FGFRs induces activation of the downstream intracellular signaling components including MEK/ERK and PI3K-AKT. However, FGF4 stimulation did not alter the expression of AKT, ERK and phosphorylated AKT and ERK, which are key signal transducers downstream of the FGFR (Figure 2A). FGF/FGFR signaling also evokes $\mathrm{Ca}^{2+}$ release from calcium stores into the cytosol, which reportedly contributes to the EMT process. We detected Orail expression and found that Orail was significantly upregulated after FGF4 treatment in both cell lines (Figure 2A). We further evaluated intracellular calcium concentration by Fluo 3-AM as a calcium indicator. Our flow cytometry experiments demonstrated that the mean fluorescence intensity (MFI) of the FGF4 group $\left(10.16 \times 10^{3}\right)$ was significantly higher than the MFI of the control $\left(1.5 \times 10^{3}\right)(P<0.01)$ (Figure $2 \mathrm{~B})$. The interaction between FGF4 and Orai1 was further confirmed by reciprocal co-IP analysis (Figure 2C). Furthermore, NVP-BGJ398 (a selective inhibitor of the FGFR) could restore intracellular calcium concentration and abolish the expression of Orail caused by FGF4 stimulation (Supplementary Figure S1), demonstrating the SOCEelevating effect of FGF4/FGFR signaling. 

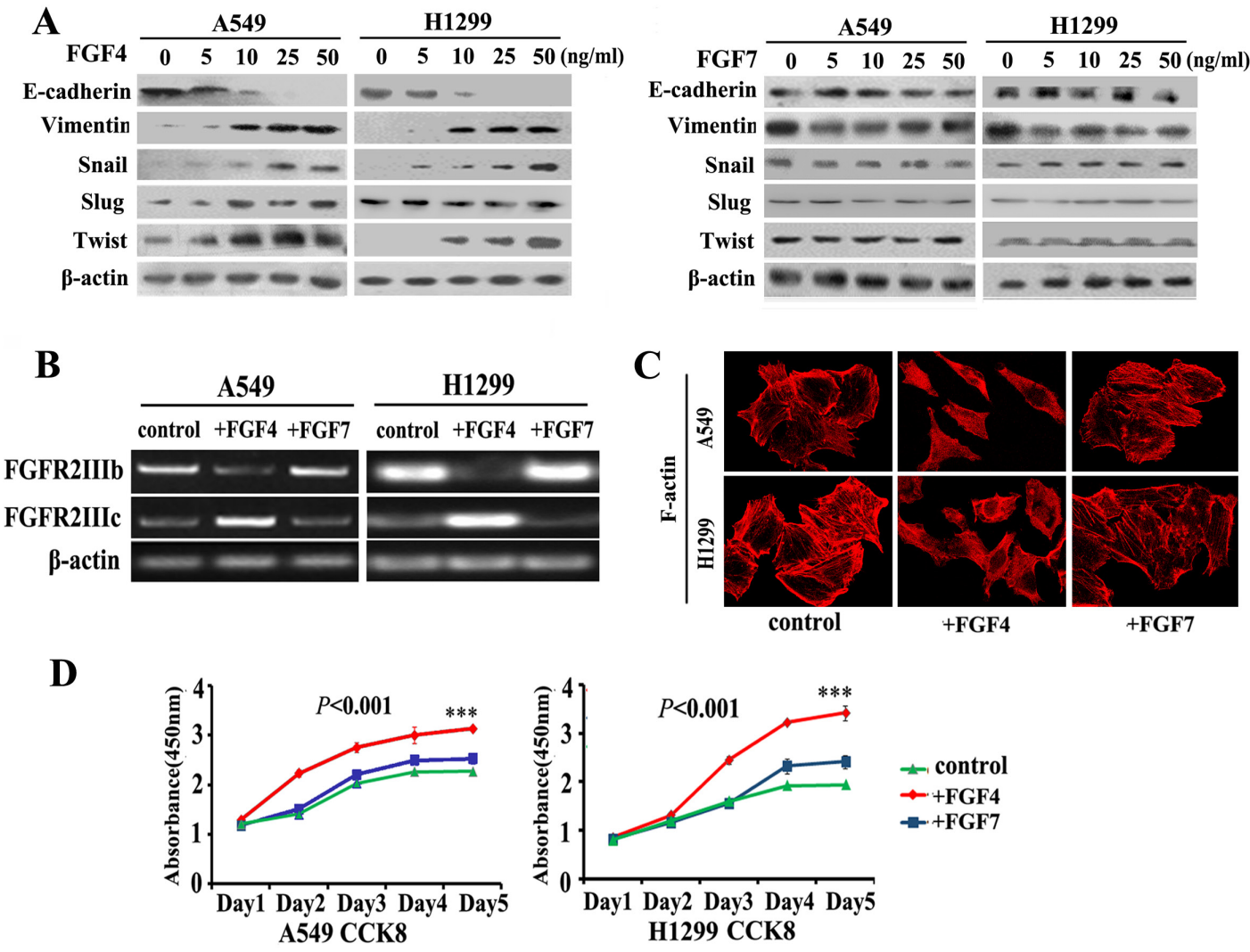

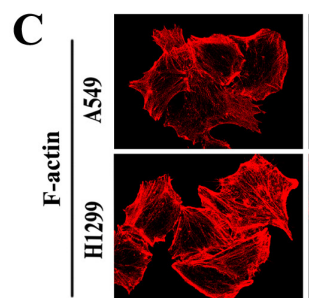

control

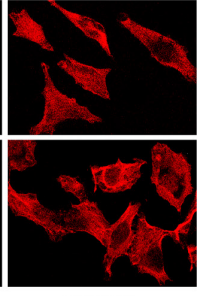

+FGF4

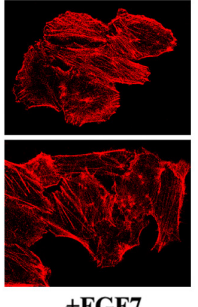

+FGF7

$\mathbf{E}$
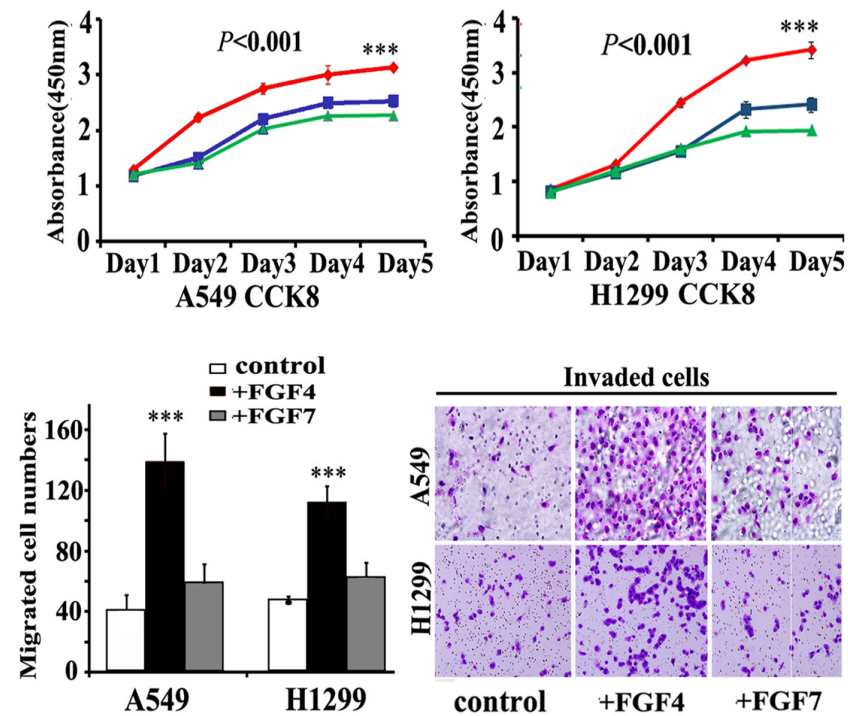

$\leftarrow$ control
$\leftarrow+$ FGF4
-+ FGF7

H1299 CCK8
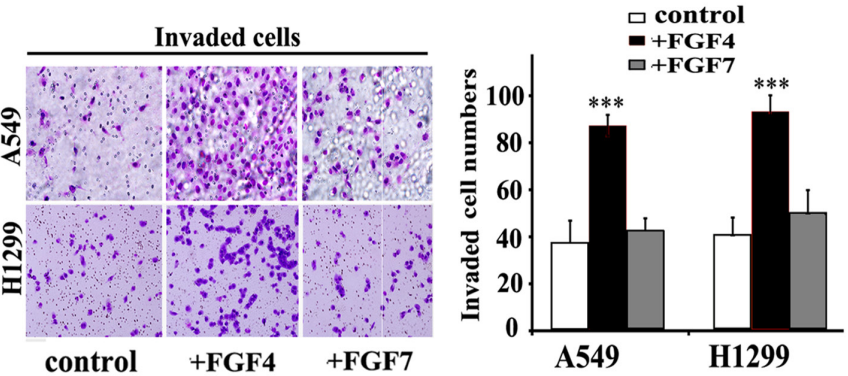

$\mathbf{F}$
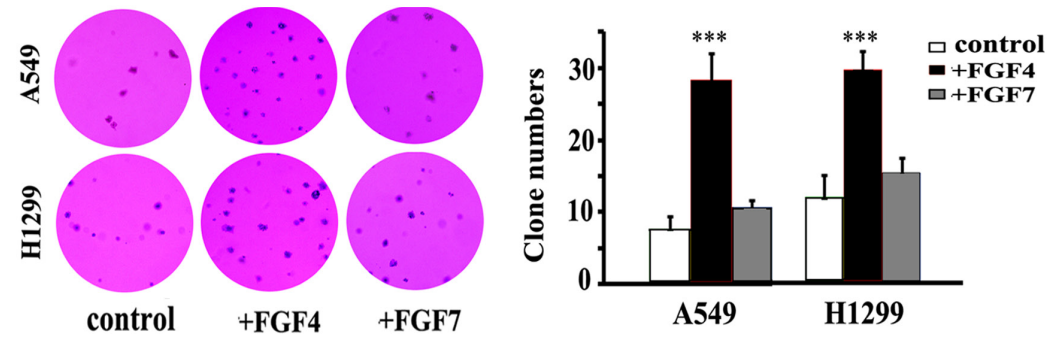

Figure 1: FGF4, not FGF7 treatment induces EMT, causes a switch from FGFR2 IIIb to FGFR2 IIIc and changes the cell morphology and behavior of A549 and H1299 lung ADC cells. A. Western blot assay measuring the expression of epithelial protein (E-cadherin), mesenchymal protein (Vimentin), and EMT transcription factors (Snail, Slug, and Twist) in A549 and H1299 cells treated with FGF4 and FGF7 at different concentrations of 0, 5, 10, and 25, and $50 \mathrm{ng} / \mathrm{mL}$, respectively. B. RT-PCR was performed to detect gene expression alterations in FGFR2 IIIb and FGFR2 IIIC. C. Cell morphology was analyzed by confocal laser scanning microscopy according to the immunolocalization of F-actin. D. CCK-8 cell proliferation assay was conducted in cells upon incubation with FGF4 or FGF7 in 1, 2, 3, 4, and 5 d, respectively. E. Transwell assay showing migration/invasion of cells treated with FGF4 or FGF7. F. Anchorage-independent growth was conducted to show the colony-initiation ability of cells exposed to FGF4 or FGF7. A549 and H1299 cells were treated with FGF4 and FGF7 at $10 \mathrm{ng} / \mathrm{mL}$ for $24 \mathrm{~h}$, respectively. The control is A549 and H1299 cells without FGF4 or FGF7 stimulation. All graphs represent the mean \pm SD of three independent experiments. The axis represents the fold change in the number of cells. ${ }^{* * *} P<0.001$. 


\section{Orai1 knockdown and BHQ impair FGF4- induced EMT in A549 and H1299 cells}

Given that SOCE is the predominant pattern for extracellular $\mathrm{Ca}^{2+}$ influx in non-excitable cells, we investigated whether SOCE contributes to the EMT response to FGF4. A549 and H1299 cells were transfected with Orail siRNA (si-1, Supplementary Figure S2) for $24 \mathrm{~h}$, and then treated with $10 \mathrm{ng} / \mathrm{ml} \mathrm{FGF} 4$. BHQ is an inhibitor of the smooth endoplasmic reticulum $\left(\mathrm{Ca}^{2+}-\mathrm{Mg}^{2+}\right)$ ATPase and functions as an endoplasmic reticulum $\mathrm{Ca}^{2+}$ pump inhibitor. We observed that both Orail knockdown and BHQ could reverse the increased cytosolic $\mathrm{Ca}^{2+}$ concentration caused by FGF4 (Figure 3A), indicating that Orail and BHQ have an inhibitory effect on $\mathrm{Ca}^{2+}$ signaling. As shown in Figure 3B, all mesenchymal factors (Vimentin, Snail and Twist) increased due to FGF4 stimulation with contrary expression of epithelial marker (E-cadherin). Western blot showed that either Orail knockdown or BHQ treatment could rescue E-cadherin inhibition and decrease Vimentin, Snail and Twist levels induced by FGF4 (Figure 3B), suggesting that SOCE was involved in FGF4-induced EMT. To rule out the different Si-Orail variations, we also transfected another Orail siRNA (Si-2) into A549 and H1299 cells and tested the expression of EMT-associated proteins by western blot (Supplementary Figure S3). The results were similar to those obtained from Orai1 siRNA (si-1).

\section{BHQ and orai1 knockdown induce restoration of epithelial phenotype, impair migration and invasion, and inhibit cell growth in monolayer cultures and anchorage-independent growth in soft agar of A549 and H1299 cells}

We next assessed whether FGF4-induced mesenchymal cell features could be blocked by SOCE inhibition. As expected, either BHQ or Orail knockdown changed the morphology of A549 and H1299 cells from a spindle-like shape to a cobble stone-like shape (Figure

A

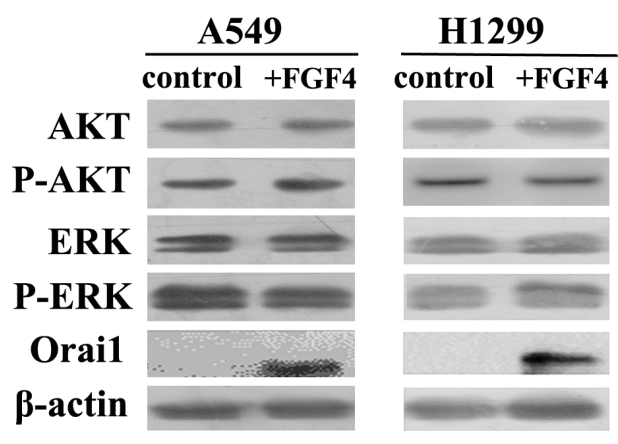

B
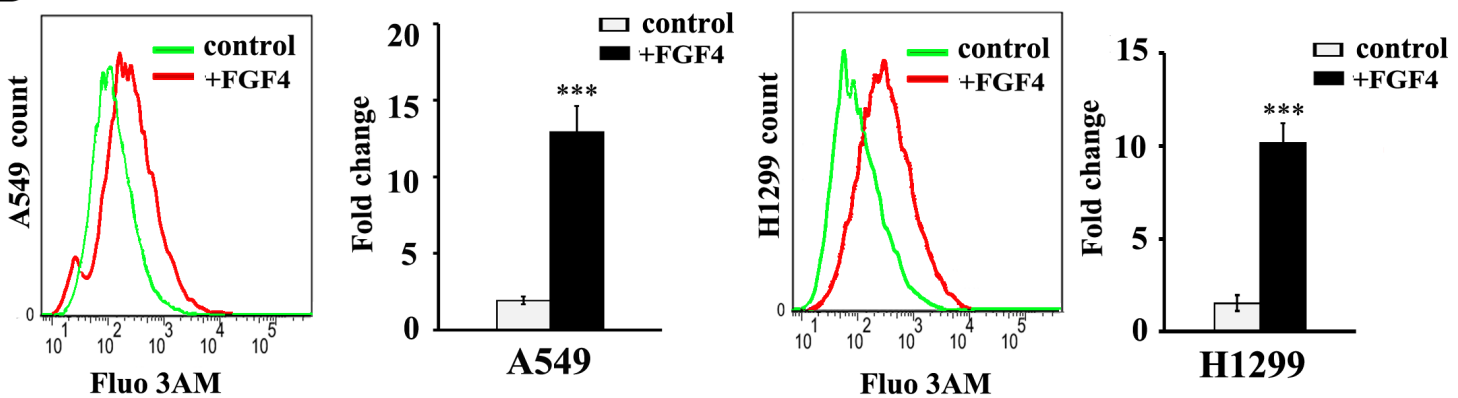

C

\begin{tabular}{c|cccccc} 
& \multicolumn{3}{c}{ A549 } & & \multicolumn{3}{c}{ H1299 } \\
\cline { 5 - 7 } \cline { 5 - 6 } Orai1 & Input & IgG & FGF4 & Input & IgG & FGF4 \\
\hline FGF4 & Input & IgG & Orai1 & Input & IgG & Orai1 \\
\hline & & & & & &
\end{tabular}

Figure 2: FGF4 elevates intracellular calcium concentration and upregulates the expression of Orai1. A549 and H1299 cells were treated with FGF4 at $10 \mathrm{ng} / \mathrm{mL}$ for $24 \mathrm{~h}$. A549 and H1299 cells without FGF4 stimulation were used as controls. A. Western blot of AKT, ERK, phosphorylated AKT, phosphorylated ERK and Orail in A549 and H1299 cells after treatment with FGF4 for 20 minutes. B. Changes in the level of intracellular $\mathrm{Ca}^{2+}$ were measured by flow cytometry. C. Reciprocal co-immunoprecipitation of endogenous FGF4 and Orail in A549 and H1299 cells. All graphs represent the mean \pm SD of three independent experiments. The axis represents the fold change in the number of cells. ${ }^{* * *} P<0.001$. 
4A), inhibited cell growth in monolayer cultures (Figure 4B), migration/invasion (Figure 4C), and colony-initiation (Figure 4D) in A549 and H1299 cells with FGF4 treatment.

\section{BHQ inhibits in vivo tumor growth and} metastasis caused by FGF4 in a H1299 xenograft mouse model, induces E-cadherin expression, and decreases the expression of Orai1 and Vimentin in tumor tissues

Using the highly metastatic H1299 lung ADC cells, we made a mouse xenograft model to assess the effect of BHQ on tumor growth and metastasis in vivo. In accordance with our in vitro findings, cells with FGF4 treatment grew into larger tumor masses than control cells and cells with FGF4+BHQ treatment (Figure 5A). Of the 10 mice injected with cells with FGF4 stimulation, two showed lung metastasis, two showed intravascular thrombus and three showed tumor invasion into skeletal muscle (Figure 5B), whereas no metastasis sites were detected in mice injected with control cells and cells with FGF4+BHQ treatment. We then performed FGF4, Orai1, E-cadherin, Vimentin and Ki-67 immunohistochemical staining on the sections of xenograft tissues. Immunohistochemical analyses showed that tumor sections from FGF4-stimulated cells exhibited a marked increase in Orail whereas tumor sections from control and FGF4+BHQ-stimulated cells revealed no or weak staining. Moreover, compared with control cells, FGF4-treated cells showed decreased

A
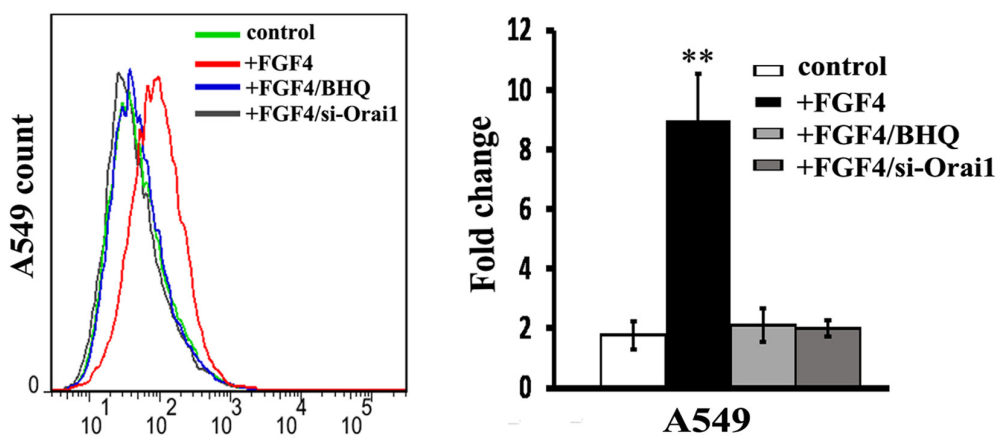

Fluo 3AM
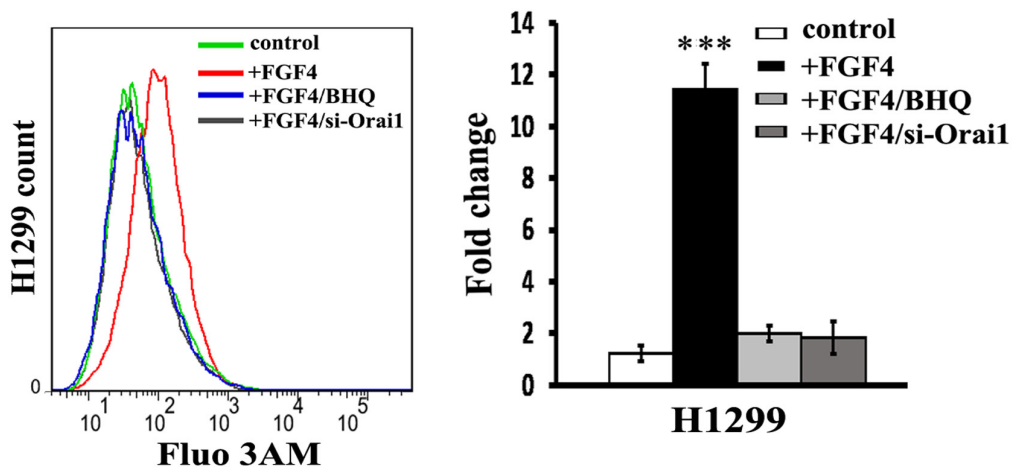

B
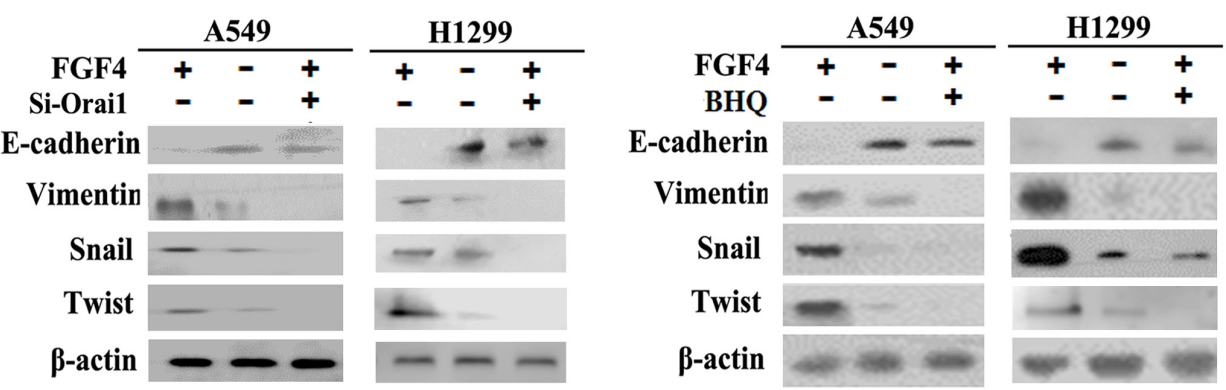

Figure 3: Orai1 knockdown and BHQ impair FGF4-induced EMT in A549 and H1299 cells. A549 and H1299 cells were transfected with Orai1 siRNA for $24 \mathrm{~h}$ or stimulated with BHQ $(50 \mu \mathrm{M})$ for $12 \mathrm{~h}$ and then treated with FGF4 $(10 \mathrm{ng} / \mathrm{mL})$ for $24 \mathrm{~h}$. A549 and H1299 cells transfected with non-sense control siRNA and without FGF4 or BHQ treatment were used as controls. A. The level of intracellular $\mathrm{Ca}^{2+}$ using Fluo 3-AM was measured by flow cytometry. B. The expression of EMT-associated proteins (E-cadherin, Vimentin, Snail and Twist) was detected by western blot. All graphs represent the mean \pm SD of three independent experiments. The axis represents the fold change in the number of cells. $* * P<0.01, * * * P<0.001$. 
E-cadherin expression and increased Vimentin and Ki67 expression. BHQ reversed FGF4-induced expression of EMT-associated proteins, including E-cadherin and Vimentin (Figure 5C). These results substantiate our findings that FGF4 induces SOCE enhancement, which contributes to promoting the EMT process in lung ADC cells.

\section{Association of FGF4 expression with clinicopathological features of lung ADC cases}

The expression patterns of FGF4 were examined on an array of 60 human lung ADC cases. Among 60 samples, 38 (63.3\%) showed positive FGF4 expression. Tumors were categorized as strong $(++)$, weak $(+)$, or

A

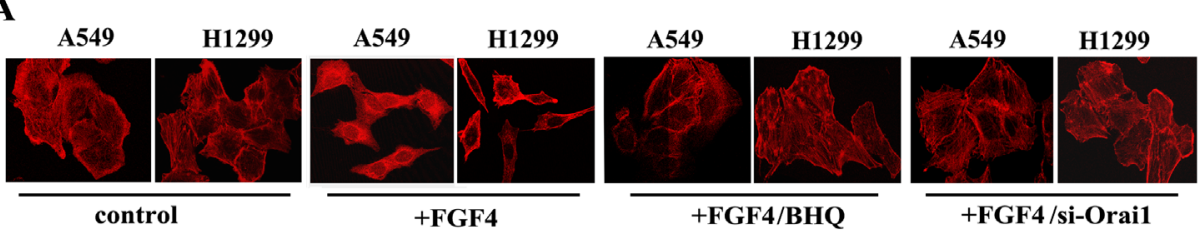

B
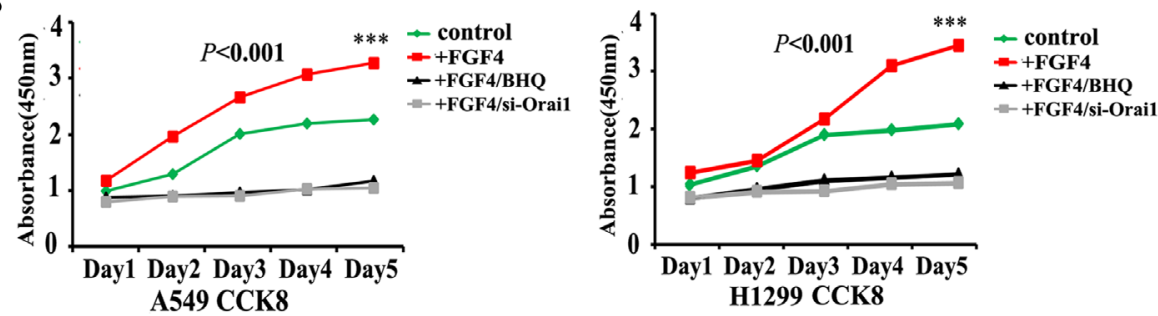

C
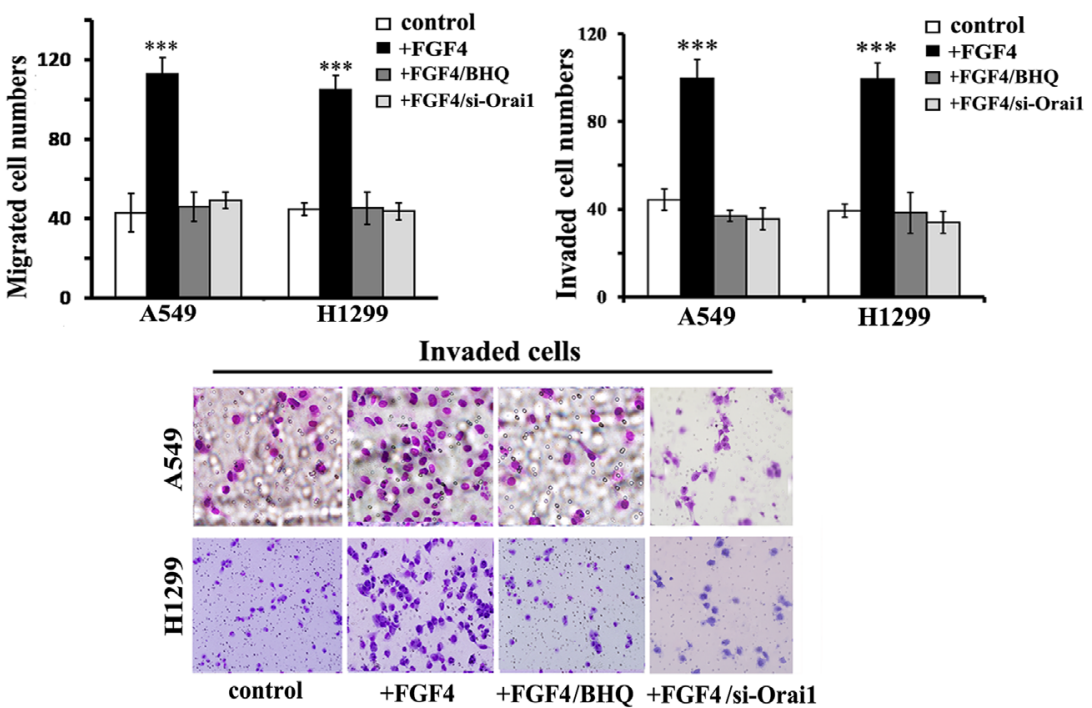

D
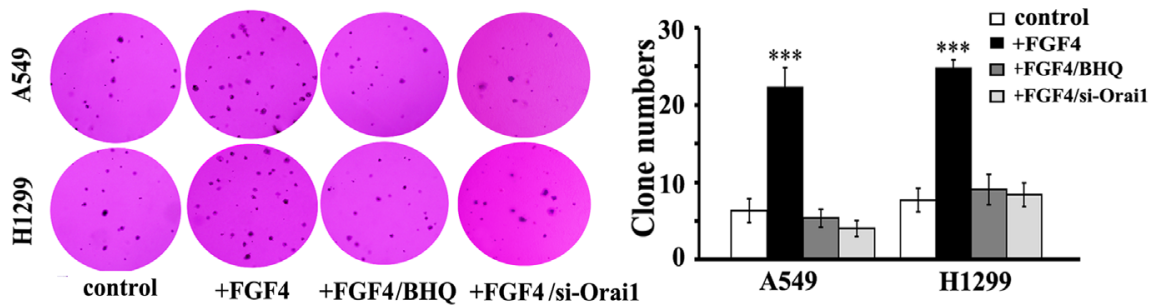

Figure 4: BHQ and Orai1 knockdown induce restoration of epithelial phenotype, impair migration and invasion, inhibit cell growth in monolayer cultures and anchorage-independent growth in soft agar of A549 and H1299 cells. A. Confocal laser scanning microscopy according to the immunolocalization of F-actin, B. CCK-8 cell proliferation assay, C. transwell assays and D. anchorage-independent growth assay of A549 and H1299 cells transfected with Orail siRNA for 24 h or stimulated with BHQ (50 $\mu \mathrm{M})$ for $12 \mathrm{~h}$ and then treated with FGF4 (10 ng/mL) for $24 \mathrm{~h}$. A549 and H1299 cells transfected with non-sense control siRNA and without FGF4 or BHQ treatment were used as controls. All graphs represent the mean $\pm \mathrm{SD}$ of three independent experiments. The axis represents the fold change in the number of cells. $* * * P<0.001$. 
negative (-) expression for FGF4. Relationships between FGF4 levels and each clinicopathological parameter are summarized in Table 1. FGF4 expression was strongly correlated with histological type $(P<0.05)$, TNM stages $(P<0.05)$, and metastasis $(P<0.05)$. The frequency of positive FGF4 expression was higher in solid predominant and micropapillary predominant samples than in ones with other histological types. Positive FGF4 expression was observed in 11 of 13 patients $(84.6 \%)$ with advanced stage carcinomas (TNM stages III and IV), and in 27 of 47 patients (57.4\%) with earlystage carcinomas (TNM stages I and II). A total of 23 (38.3\%) lung ADC patients experienced metastasis. The patients with positive FGF4 expression had a higher rate

A

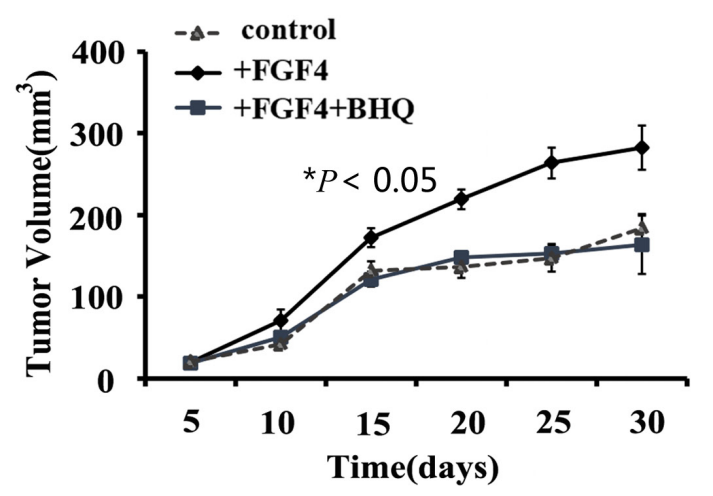

B

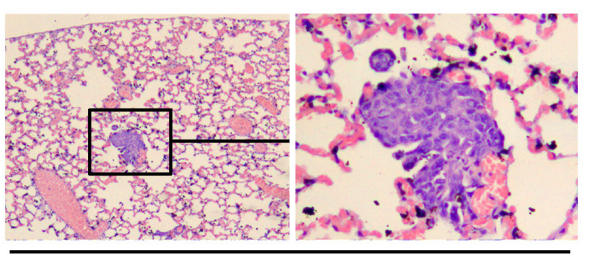

Lung metastasis

C
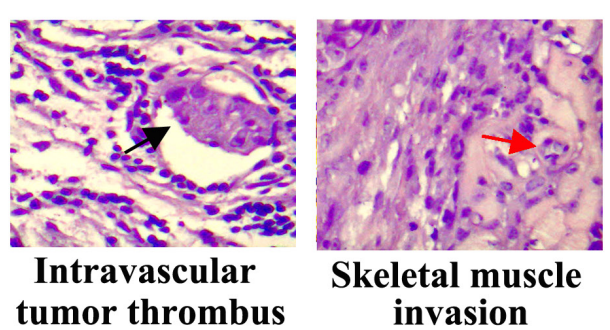

Skeletal muscle invasion

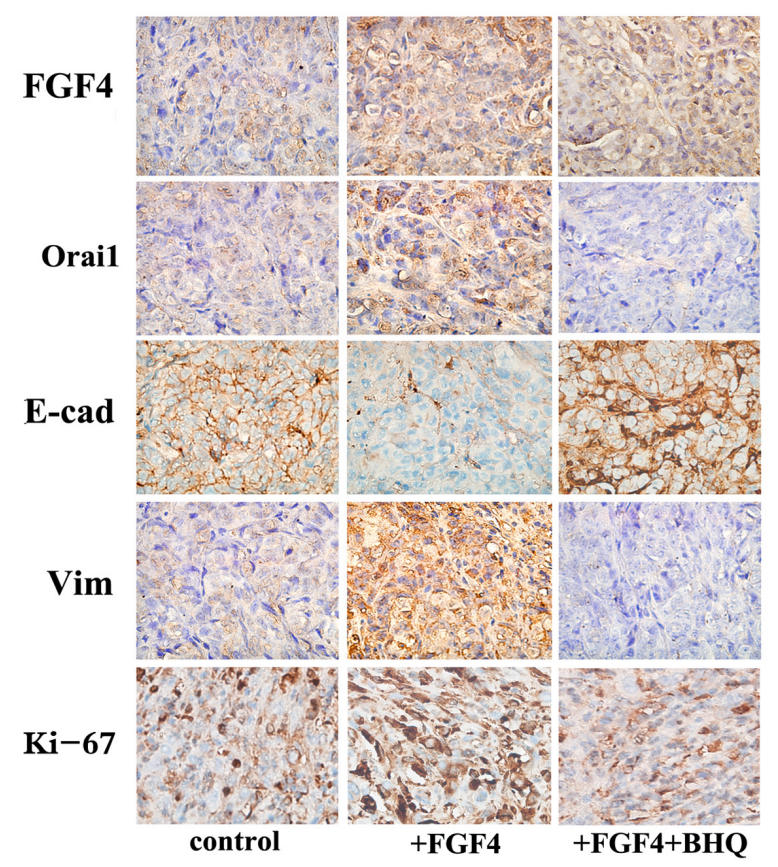

Figure 5: BHQ inhibits in vivo tumor growth and metastasis caused by FGF4 in a H1299 xenograft mouse model, induces the expression of E-cadherin, and decreases the expression of Orail and Vimentin in tumor tissues. A. H1299 cells with FGF4 treatment grew into larger tumor masses than the control cells and the cells with FGF4+BHQ treatment. B. Mice injected with H1299 cells with FGF4 stimulation showed lung metastasis, intravascular thrombus and skeletal muscle invasion. H\&E staining, $(200 \times)$. C. Immunohistochemical staining of FGF4, Orai1, E-cadherin Vimentin and Ki-67 expression in harvested H1299 xenograft mouse samples. $200 \times$. All graphs represent mean $\pm \mathrm{SD}$ of three independent experiments. $* P<0.05$. 
Table 1: Correlation between FGF4 and clinicopathologic characteristics of lung adenocarcinoma

\begin{tabular}{|c|c|c|c|c|c|c|}
\hline \multirow{2}{*}{ Variable } & \multirow{2}{*}{ Total(\%) } & \multicolumn{3}{|c|}{ FGF4 expression } & \multirow{2}{*}{$\chi^{2}$} & \multirow{2}{*}{$P$ value } \\
\hline & & - & + & ++ & & \\
\hline \multicolumn{7}{|l|}{ Age } \\
\hline$<50$ & $7(11.7)$ & $4(57.1)$ & $1(14.3)$ & $2(28.6)$ & \multirow{2}{*}{3.021} & \multirow{2}{*}{0.221} \\
\hline$\geq 50$ & $53(88.3)$ & $18(34]$ & $26(49.1)$ & $9(17)$ & & \\
\hline \multicolumn{7}{|l|}{ Sex } \\
\hline Male & $26(43.3)$ & $10(38.5)$ & $9(34.6)$ & $7(26.9)$ & \multirow{2}{*}{2.986} & \multirow{2}{*}{0.225} \\
\hline Female & $34(56.7)$ & $12(35.3)$ & $18(52.9)$ & $4(11.8)$ & & \\
\hline \multicolumn{7}{|l|}{ Lobe of primary tumor } \\
\hline Upper & $37(61.7)$ & $14(37.8)$ & $16(43.2)$ & $7(18.9)$ & \multirow{2}{*}{0.120} & \multirow{2}{*}{0.942} \\
\hline Middle/Lower & $23(38.3)$ & $8(34.8)$ & $11(47.8)$ & $4(17.4)$ & & \\
\hline \multicolumn{7}{|l|}{ Tumor size $(\mathrm{cm})$} \\
\hline$\geq 3$ & $28(46.7)$ & $9(31.2)$ & $14(50)$ & $5(17.9)$ & \multirow{2}{*}{0.591} & \multirow{2}{*}{0.744} \\
\hline$<3$ & $32(53.3)$ & $13(40.6)$ & $13(40.6)$ & $6(18.8)$ & & \\
\hline \multicolumn{7}{|l|}{ Histological type } \\
\hline Lepidic predominant & $21(35.0)$ & $12(57.1)$ & $7(33.3)$ & $2(9.5)$ & \multirow{5}{*}{15.952} & \multirow{5}{*}{$0.043^{*}$} \\
\hline Acinar predominant & $17(28.3)$ & $4(23.5)$ & $12(70.6)$ & $1(5.9)$ & & \\
\hline Solid predominant & $10(16.6)$ & $3(30.0)$ & $4(40.0)$ & $3(30.0)$ & & \\
\hline Micropapillary predominant & $8(13.3)$ & $1(12.5)$ & $3(37.5)$ & $4(50.0)$ & & \\
\hline Papillary predominant & $4(6.7)$ & $2(50.0)$ & $1(25.0)$ & $1(25.0)$ & & \\
\hline \multicolumn{7}{|l|}{ TNM stage } \\
\hline TNM I & $33(55.0)$ & $18(54.5)$ & $11(33.3)$ & $4(12.1)$ & \multirow{4}{*}{17.197} & \multirow{4}{*}{$0.009^{*}$} \\
\hline TNM II & $14(23.3)$ & $2(14.3)$ & $10(71.4)$ & $2(14.3)$ & & \\
\hline TNM III & $7(11.7)$ & $1(14.3)$ & $2(28.6)$ & $4(57.1)$ & & \\
\hline TNM IV & $6(10.0)$ & $1(16.7)$ & $4(66.7)$ & $1(16.7)$ & & \\
\hline \multicolumn{7}{|l|}{ Metastasis } \\
\hline Present & $23(38.3)$ & $4(17.4)$ & $13(56.5)$ & $6(26.1)$ & \multirow{2}{*}{6.103} & \multirow{2}{*}{$0.047^{*}$} \\
\hline Absent & $37(61.7)$ & $18(48.6)$ & $14(37.8)$ & $5(13.5)$ & & \\
\hline
\end{tabular}

*Significantly different.

of metastasis $(19 / 38,50.0 \%)$ than those with negative FGF4 expression $(4 / 22,18.2 \%)$. No correlations were found between FGF4 expression level and patient age or gender, tumor size or location. Interestingly, we observed differences in FGF4 expression within tumors, with strong FGF4 expression observed in tumor cells located close to stroma (Figure 6A). We also analyzed FGF4 expression in 21 sets of matched specimens (including lung ADC primary foci and lymph node metastatic foci) obtained from one patient to gain a better picture of FGF4 expression in the lung ADC progression. Table 2 and Figure 6B show that FGF4 expression in the lymph node metastatic foci was higher than in the primary foci $(P<0.05)$, implying that FGF4 may be involved in the EMT process of lung ADC cells.

\section{Expression of FGF4 is concomitant with EMT immunohistochemical features and Orai1 expression}

To further assess the relationship between FGF4 and EMT in human lung ADC tissues, we investigated the expression of E-cadherin and Vimentin. As shown in Table 3 and Figure 7A, the FGF4-negative group showed higher 
E-cadherin expression $(P<0.05)$ and lower Vimentin expression $(P<0.05)$ than the weakly and strongly positive groups, thereby confirming the EMT-promoting effect of FGF4 on lung ADC.

FGF4 and Orail expression in the 60 specimens was analyzed to assess the relationship between FGF4 and SOCE. Orail expression was higher $(P<0.05)$ in the samples with weakly and strongly positive FGF4 expression than in those with negative FGF4 expression (Table 4 and Figure 7B). These findings suggested that FGF4 may induce EMT by elevating SOCE.

\section{DISCUSSION}

Lung cancer is a leading cause of cancer-associated death worldwide. ADC accounts for almost $40 \%$ of all lung malignancies and its incidence has rapidly increased in recent years [12]. Several targeted drugs against growth factors or their receptor tyrosine kinases have been used to treat $\mathrm{ADC}[4,11-13,28-30]$; however, the prognosis of patients remains dismal. A better understanding of the molecular mechanisms involved in the development and progression of lung ADC might facilitate the development of novel treatment strategies that improve patient prognosis.

FGF/FGFR signaling is involved in many physiological and pathological processes. In general, FGFRs encoding exon IIIb (FGFR-IIIb) are expressed in epithelial cells, whereas FGFRs encoding exon IIIc (FGFR-IIIc) are expressed in mesenchymal cells [7, 14, 16, 31]. In EMT, FGFR2-IIIb switches to FGFR2-IIIc.
FGF4, which binds FGFR2-IIIc with high affinity, was previously reported to be highly expressed in advancedstage and poor-prognosis cases of serous ovarian cancer [32]. FGF7, which exerts its biological effects by binding to FGFR-IIIb, was observed to promote tumor angiogenesis and migration of pancreatic cancer [33]. In this study, we found that FGF4, but not FGF7, could downregulate E-cadherin expression and upregulate the expression of Vimentin and the two EMT transcription factors Snail and Twist. We also demonstrated that FGF4 treatment could cause a switch from FGFR2-IIIb to FGFR2-IIIc. Except for altering the expression of differentiation proteins, FGF4 can induce cancer cells to be more mesenchymal-like and enhance their proliferation, invasion/migration, and colony initiation abilities. Experiments conducted on human lung ADC tissue samples showed that FGF4 expression was relatively high in lymph-node metastatic foci and in lung ADC tissues with metastasis. Mouse experiments also indicated that FGF4 treatment may induce tumor metastasis. Immunohistochemical staining of human and mice tissue samples demonstrated that FGF4 could induce a phenotype displaying EMT. These results were consistent with a previous study, in which FGF4 was found to maintain trophoblast stem cells under undifferentiating, self-renewing conditions and display decreased E-cadherin expression and increased Slug and Twist expression [34].

Following FGF binding and receptor dimerization, downstream components including AKT and ERK kinases are activated to initiate several signaling pathways. FGF/ FGFR signaling also confers selective and strong binding to phospholipase $\mathrm{Cc}$ for the catalysis of phosphatidylinositol

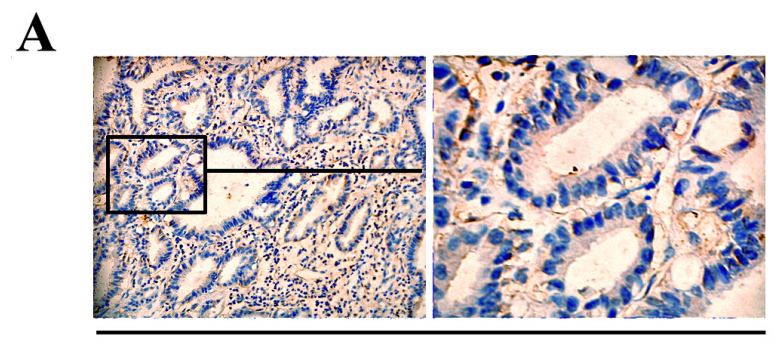

Tumor center

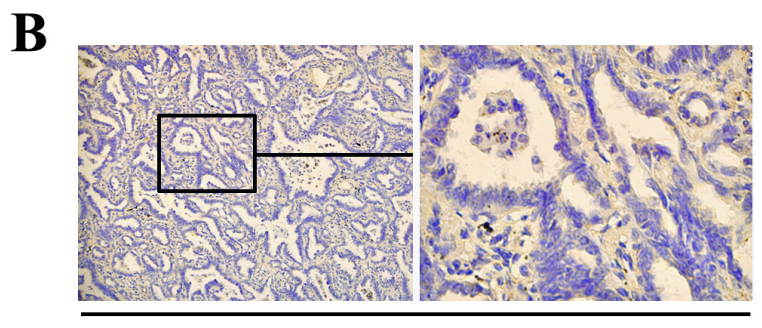

Primary foci

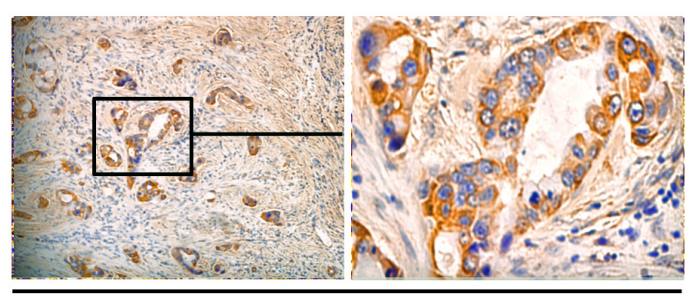

Invasive front

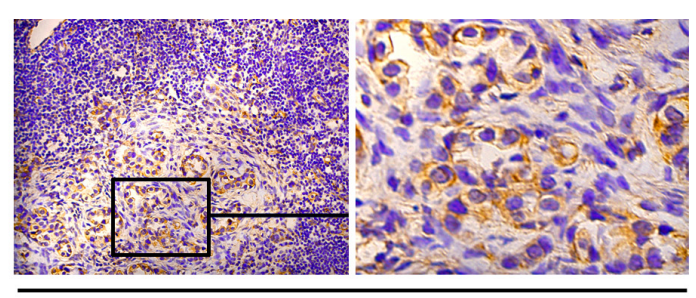

Metastatic foci in lymph node

Figure 6: Differences in FGF4 levels within human ADC tissues and in matched lung ADC primary foci and lymph node metastatic foci. Immunohistochemical staining of FGF4 showed A. different FGF4 levels in the tumor center and the invasive front of the same lung ADC tissue sample $(200 \times)$, B. different FGF4 levels inlung ADC primary foci and lymph node metastatic foci from a same patient $(200 \times)$. 
Table 2: FGF4 expression in matched lung adenocarcinoma primary foci and metastatic foci in lymph nodes

\begin{tabular}{|c|c|c|c|c|c|c|}
\hline & \multicolumn{4}{|c|}{ FGF4 expression n(\%) } & \multirow{2}{*}{$\chi^{2}$} & \multirow{2}{*}{$P$ value } \\
\hline & Total & - & + & ++ & & \\
\hline Primary foci & 21 & $10(47.6)$ & $9(42.9)$ & $2(9.5)$ & & \\
\hline Metastatic foci & 21 & $5(23.8)$ & $7(33.3)$ & $9(42.9)$ & 6.371 & $0.041 *$ \\
\hline Total & 42 & $15(35.7)$ & $16(38.1)$ & $11(26.2)$ & & \\
\hline
\end{tabular}

*Significantly different.

Table 3: Correlation between expression of FGF4 and epithelial-mesenchymal transition-associated proteins

\begin{tabular}{|c|c|c|c|c|c|c|}
\hline \multirow{2}{*}{ Variable } & \multirow{2}{*}{ Total(\%) } & \multicolumn{3}{|c|}{ FGF4 expression } & \multirow{2}{*}{$\chi^{2}$} & \multirow{2}{*}{$P$ value } \\
\hline & & - & + & ++ & & \\
\hline \multicolumn{7}{|c|}{ E-cadherin expression } \\
\hline- & $10(16.7)$ & $1(10.0)$ & $4(40.0)$ & $5(50.0)$ & 8.958 & $0.011 *$ \\
\hline+ & $50(83.3)$ & $21(42.0)$ & $23(46.0)$ & $6(12.0)$ & & \\
\hline \multicolumn{7}{|c|}{ Vimentin expression } \\
\hline $\begin{array}{l}- \\
+\end{array}$ & $\begin{array}{c}52(86.7) \\
8(13.3)\end{array}$ & $\begin{array}{c}21(40.4) \\
1(12.5)\end{array}$ & $\begin{array}{c}25(48.1) \\
2(25.0)\end{array}$ & $\begin{array}{l}6(11.5) \\
5(62.5)\end{array}$ & 12.112 & $0.002 *$ \\
\hline
\end{tabular}

*Significantly different.
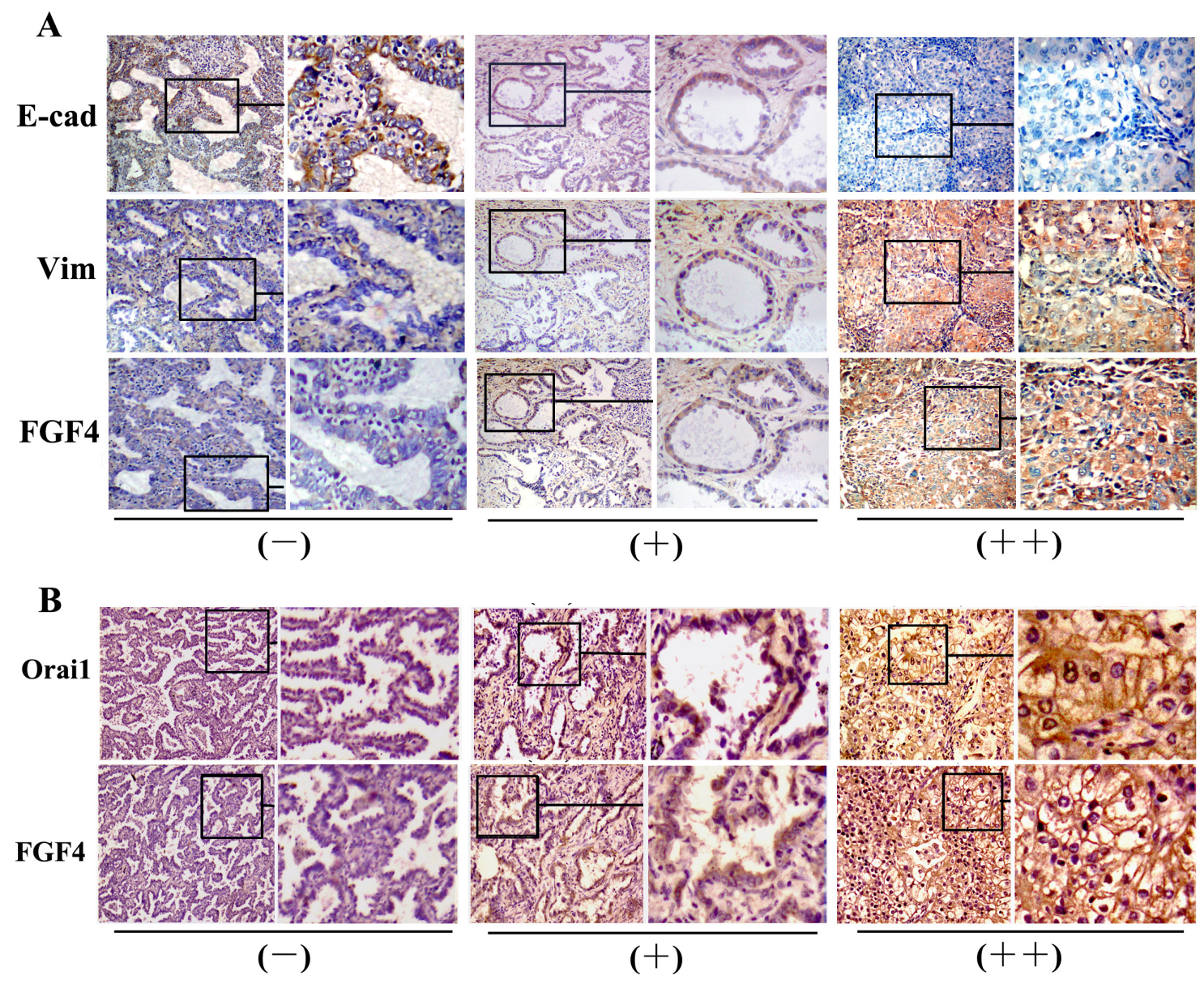

Figure 7: Expression of FGF4 is concomitant with EMT immunohistochemical features and Orai1 expression. A. Immunohistochemical staining of E-cadherin, Vimentin, and B. Orai1 in the three groups with different FGF4 levels $(-,+,++)$ in human lung ADC tissue samples $(200 \times)$. 
Table 4: Correlation between expression of FGF4 and Orai1

\begin{tabular}{|c|c|c|c|c|c|c|}
\hline \multirow{2}{*}{ Variable } & \multirow{2}{*}{ Total(\%) } & \multicolumn{3}{|c|}{ FGF4 expression } & \multirow{2}{*}{$\chi^{2}$} & \multirow{2}{*}{$P$ value } \\
\hline & & - & + & ++ & & \\
\hline \multicolumn{7}{|c|}{ Orail expression } \\
\hline- & $25(41.7)$ & $15(60)$ & $6(24)$ & $4(16)$ & \multirow{3}{*}{12.482} & \multirow{3}{*}{$0.014 *$} \\
\hline+ & $30(50)$ & $6(20)$ & $9(63.3)$ & $5(16.7)$ & & \\
\hline++ & $5(8.3)$ & $1(20)$ & $2(40)$ & $2(40)$ & & \\
\hline
\end{tabular}

*Significantly different.

diphosphate to generate two effectors, namely, diacylglycerol and IP3 [1, 2, 17, 19]. IP3 then binds to the IP3 receptor on the endoplasmic reticulum membrane and evokes $\mathrm{Ca}^{2+}$ release from calcium stores into the cytosol. Once the STIM protein senses a $\mathrm{Ca}^{2+}$ level drop in the endoplasmic reticulum, it binds with Orai channels and elicits $\mathrm{Ca}^{2+}$ influx. This process is known as SOCE [19, $25,26,35]$. In this study, we observed that the expression of phosphorylated AKT and ERK in FGF4-stimulated cells were not increased compared with control cells. On the other hand, FGF4 treatment remarkably upregulated Orail expression and elevated the intracellular calcium concentration. In the human lung ADC tissue samples, we observed higher levels of Orail expression in the FGF4 strong expression group than in the weak and negative expression groups. A similar result was observed in the mouse xenograft model. This suggests that FGF4 may exert its EMT-promoting effect by elevating SOCE and not through the AKT and ERK signaling pathways.

We also showed that either SOCE pharmacological inhibitor BHQ or Orail knockdown could abrogate the induction of the EMT response to FGF4 in vitro. Furthermore, BHQ could restrained tumor formation and metastasis in an mouse xenograft model. All of these results indicated that FGF4-induced EMT correlates with enhancement of SOCE. SOCE promotes malignant phenotypes [19] and reduces the production of VEGF, tissue factor and COX-2 (which are essential for angiogenesis) in cancer cells $[26,36]$. Aberrant SOCE induces directional migration and inhibition of SOCE results in the upregulation of $\mathrm{p} 21$ and the downregulation of Cdc $25 \mathrm{C}$, cyclinE, cyclinD, CDCK2, and CDCK4, which eventually elicit cell-cycle arrest [37]. The clinical diagnostic and prognostic potential of Orai1 and STIM1 have also been demonstrated in many cancer types, including prostate cancer, melanoma, NSCLC, and colorectal cancer $[19,26]$.

SOCE has been reported to be involved in TGF- $\beta$ or EGF-induced EMT in breast cancer cells [27, 21]. Similarly, here we report that SOCE helps to drive the FGF4-induced EMT program. However, inconsistent results have been reported. A study by Niu et al. showed that FGF7 stimulates cell proliferation in pancreatic ductal epithelial cells [38]. According to previous reports, FGFs exert different actions depending on the type and origin of cells examined [39]. Future studies assessing the precise function of FGFs and their receptors in the EMT and tumor progression are needed. On the other hand, our results contradict a recent study by Davis et al., who demonstrated that EGF-induced EMT in MDAMB-468 breast cancer cells was associated with reduced SOCE [40]. In addition to FGF4/FGFR signaling, several other signaling pathways (e.g., TGF $\beta$, EGF, Notch, Wnt) have also been shown to induce EMT [5, 22, 41, 42]. Interestingly, some of these pathways are found among the functional gene sets associated with FGF/FGFR signaling and SOCE regulation. Future investigations may reveal how SOCE changes in EMT induced by alternative cytokines and signaling pathways.

\section{MATERIALS AND METHODS}

\section{Cell culture and growth factor stimulation}

Human lung ADC cell lines A549 and H1299 were obtained from the Cell Resource Center, Institute of Basic Medical Sciences, Chinese Academy of Medical Sciences, Peking Union Medical College (Beijing, China). Both cell lines were cultured in recommended medium (RPMI-1640) supplemented with 10\% fetal bovine serum (Hyclone, Logan, Utah, USA) at $37{ }^{\circ} \mathrm{C}$ in $5 \% \mathrm{CO}_{2}$ incubator. Sometimes, $10 \%$ fetal bovine serum was changed to serum-starved condition depending on the experiment. After $24 \mathrm{~h}$ of starvation in serum-free medium, cells were treated with FGF4 and FGF7 (PeproTech Rocky Hill, NJ, USA).

\section{Antibodies and reagents}

The rabbit anti-Orai1, rabbit anti-Snail, rabbit antiVimentin and mouse anti-Ki-67 were obtained from Santa Cruz Biotechnology (Santa Cruz, CA, USA). Rabbit anti-Twist, mouse anti-Vimentin, rabbit anti-AKT, rabbit anti-p-AKT, rabbit anti-ERK and rabbit anti-p-ERK were obtained from Cell Signaling Technology (Beverly, MA, USA). Rabbit anti-Slug and rabbit anti-E-cadherin were from Abcam (Cambridge, UK). Mouse anti- $\beta$-actin was obtained from Tianjin Sungene Biotech Co, Ltd. BGJ398 was obtained from Selleck Chemicals (Houston, TX, 
USA). 2,5-di-tert-butylhydroquinone (BHQ) was obtained from Sigma (St. Louis, MO, USA).

\section{Western blot analysis}

Cell lysates were prepared using RIPA lysis buffer. Protein $(30-50 \mu \mathrm{g} / \mathrm{lane})$ was separated by SDS-PAGE and transferred to polyvinylidene difluoride membranes. Subsequently, the membranes were incubated overnight with primary antibodies (E-cadherin 1:5000, Vimentin 1:1000, Snail 1:500, Slug 1:500, Twist 1:500, Orai1 1:500, AKT 1:1000, p-AKT 1:1000, ERK 1:1000, p-ERK1:1000 and $\beta$-actin 1:5000) at $4{ }^{\circ} \mathrm{C}$. Blots were washed in TBS containing $0.1 \%$ Tween 20 and labeled with goat anti-mouse IgG-HRP or goat anti-rabbit IgG-HRP (1:5000; Santa Cruz Biotechnology). Equal loading of samples was confirmed by probing the membranes with $\beta$-actin antibody.

\section{RNA isolation, cDNA synthesis and RT-PCR analysis}

RNA was isolated from cells using the RNeasy mini kit (QIAGEN Hilden, Germany) or TRIzol reagent (Invitrogen Carlsbad, CA, USA). Reverse transcription was performed with high capacity cDNA reverse transcription kits (Takara Biotechnology, Shiga, Japan) according to the manufacturer's instructions. RT-PCR $\left(98^{\circ} \mathrm{C}\right.$ for $5 \mathrm{~min}, 34$ cycles at $98{ }^{\circ} \mathrm{C}$ for $30 \mathrm{~s}, 55^{\circ} \mathrm{C}$ for $30 \mathrm{~s}$, and $72{ }^{\circ} \mathrm{C}$ for 30 $\mathrm{s}$, with an extension step of $10 \mathrm{~min}$ at $72{ }^{\circ} \mathrm{C}$ at the end of the last cycle) was carried out using $2 \times \mathrm{PCR}$ Solution Premix Taq (R004A, Takara Biotechnology Shiga, Japan). PCR products were run on $1 \%$ agarose gel. The primers FGFR2IIIb: forward: 5'-GCA CTC GGG GAT AAA TAG TTC -3'; reverse: 5'-TGT TTT GGC AGG ACA GTG AGC3'; FGFR2IIIc: forward: 5'-GTT AAC ACC ACG GAC AAA GAG-3'; reverse: 5'-GGC GCT GGC AGA ACT GTC AAC -3'; FGF4: forward: 5'-ATG TCG GGG CCC GGG ACG GCC -3'; reverse: 5'-TCA CAG CCT GGG GAG GAA GTG -3'; FGF7: forward: 5'-ATG CAC AAA TGG ATA CTG ACA -3'; reverse: 5'-TTA TTG CCA TAG GAA GAA AGT -3'.

\section{Small interfering RNAs and transfections}

The Orail gene-specific short interfering (si1: CCTTCGGCCTGATCTTTAT si-2: GCAACGTGC ACAATCTCAA si-3: GCTCACTGGTTAGCCATAA), and non-specific control siRNA were purchased from RiboBio (Shanghai, China). A549 or H1299 cells were transiently transfected using Fugene (Life Technologies, Carlsbad, CA, USA) according to the manufacturer's instructions. There were 3 specific siRNAs and protein expression levels were detected by western blot to evaluate the efficiency of knockdown after $24 \mathrm{~h}$ transfection.

\section{Phalloidin staining of F-actin}

Cells were cultured on sterile glass cover slips and placed in serum-free medium transfected with FGF4/
si-Orai1 or added with FGF4, FGF7 or FGF4/BHQ for $24 \mathrm{~h}$ before staining. Cells were fixed with ice-cold $4 \%$ paraformaldehyde for $10 \mathrm{~min}$, quenched with $50 \mathrm{mmol} / \mathrm{L}$ $\mathrm{NH}_{4} \mathrm{Cl}$ for $5 \mathrm{~min}$, permeabilized in $0.2 \%$ Triton X-100 for $10 \mathrm{~min}$. The slips were incubated with the phalloidin conjugated to Alexa 594 for $40 \mathrm{~min}$ in the dark. Cells were washed five times with PBS and visualized with a confocal laser scanning microscopy (Leica TCS SP5, Leica Microsystems, Wetzlar, Germany).

\section{Cell proliferation assay}

Cell proliferation was evaluated using the Cell Counting Kit-8 (CCK-8) assay (Dojindo Laboratories, Kumamoto, Japan). Cells $\left(8 \times 10^{3}\right.$ cells/well) were seeded into 96-well flat-bottomed plates in $100 \mu \mathrm{L}$ of complete medium. The cells were incubated overnight to allow for cell attachment and recovery and then added with or without FGF4, FGF7 for different periods $(1,2,3$, 4, or 5 days). In some experiments, cells were transfected with si-Orail or mixed with $50 \mu \mathrm{M}$ BHQ. Before detection, cells were incubated with CCK-8 solution $(10 \mu \mathrm{L})$ for $3 \mathrm{~h}$. Absorbance was measured at $450 \mathrm{~nm}$ using a microplate reader according to the manufacturer's instruction.

\section{Migration/invasion assay}

Cell motility was examined in a transwell assay using 24 -well plates with uncoated inserts $(8 \mu \mathrm{m}$ pore, BD Biosciences San Jose, CA, USA) to examine migration or Matrigel-coated inserts to assess invasiveness. Briefly, $600 \mu \mathrm{L}$ culture medium supplemented with FGF4 or FGF7 were added to the lower part of the chamber, whereas cells $\left(1 \times 10^{5}\right.$ cells $)$ in $200 \mu \mathrm{L}$ culture medium were seeded to the upper part. For some experiments, cells were transfected with si-Orail or mixed with $50 \mu \mathrm{M}$ BHQ. After incubation at $37{ }^{\circ} \mathrm{C}$ with $5 \% \mathrm{CO}_{2}$ for $24 \mathrm{~h}$, the passed cells were fixed and stained. The entire membrane was counted by light microscopy in six random fields.

\section{Soft agar colony formation assay}

The agar was plated in 2 layers. A $0.6 \%$ agar dilution (Difco Agar Nobel) was placed on the bottom of a 6-well plate. Cells were seeded at a density of $1 \times 10^{4} / \mathrm{ml}$ and mixed into the $0.3 \%$ agar top layer that had been prepared with or without FGF4 or FGF7. For some experiments, cells were transfected with si-Orail or added with $50 \mu \mathrm{M}$ BHQ. Two weeks later, the cells were stained with $0.02 \%$ crystal violet, and photographed at 10 random fields in each well.

\section{Flow cytometry for intracellular calcium}

Levels of intracellular calcium concentration were measured by flow cytometry. Cells were washed with Hank's balanced salt solution (HBSS) three times, loaded with $1 \mathrm{ml} \mathrm{HBSS}$ containing $5 \mu \mathrm{mol} / \mathrm{L}$ Fluo 3-AM (Dojindo, Japan) and incubated at $37^{\circ} \mathrm{C}$ for $60 \mathrm{~min}$. Cells were 
washed with HBSS three times and incubated with HBSS for $30 \mathrm{~min}$. The cells were collected and resuspended in PBS. The intracellular calcium concentration in a population of 50,000 cells was measured using an Accuri C6 flow cytometer (BD Biosciences San Jose, CA, USA).

\section{Co-immunoprecipitation (Co-IP) assay}

The cells were washed with PBS, lysed in ice-cold Co-IP lysis buffer and protease inhibitor cocktail, and were then incubated on ice for $30 \mathrm{~min}$. The insoluble material was pelleted at $12,000 \mathrm{~g}$ for $15 \mathrm{~min}$ at $4{ }^{\circ} \mathrm{C}$, precleared by incubation with protein A/G PLUS-Agarose (Santa Cruz Biotechnology, Inc.) and the aliquots were co-immunoprecipitated with anti-FGF4 primary antibody or $\operatorname{IgG}$ followed by incubation with protein $\mathrm{A} / \mathrm{G}$ PLUS-Agarose beads for a further $1 \mathrm{~h}$ at $4{ }^{\circ} \mathrm{C}$. The immunoprecipitated complexes were washed with co-IP washing buffer [200 mM Tris ( $\mathrm{pH} 7.4$ ), $150 \mathrm{mM} \mathrm{NaCl}, 0.5 \%$ NP-40, and $1 \mathrm{mM}$ EDTA] three times. Immunoprecipitated proteins were separated by $10 \%$ SDS-PAGE. Then western blot was performed as described above.

\section{Xenograft mouse model}

Thirty mice (Wei Tong Li Hua Experimental company, Beijing, China) were randomly divided into three groups and received $3 \times 10^{6} \mathrm{H} 1299$ cells by subcutaneous injection in the right groin. In the FGF4 and FGF4/BHQ groups, the mice were given three subcutaneous injections of FGF4 (500 ng/mouse) per week. In the FGF4/BHQ group, the mice were given BHQ $(1 \mathrm{mg} / \mathrm{kg})$ three times per week after having been injected with FGF4 during fifteen days. All animal care and handling procedures were approved by the Institutional Animal Use and Care Committee of Tianjin Medical University. Tumor size was measured every 5 days for 30 days. Tumor volumes were calculated using the following formula: volume $=\left(\right.$ length $\times$ width $\left.^{2}\right) / 2$. Tumor samples were formalin fixed, paraffin embedded and subjected to H\&E and immunohistochemical staining.

\section{Hematoxylin-eosin staining}

Tissues were fixed in $10 \%$ neutral buffered formalin for $24 \mathrm{~h}$, embedded in paraffin wax, cut into 4 $\mu \mathrm{m}$ thicknesses, deparaffinized in xylene, and processed with graded ethanol series. Sections were stained with Hematoxylin and Eosin and visualized using an Olympus BX51 microscope.

\section{Clinical samples}

We collected 60 formalin-fixed, paraffin-embedded lung ADC tissue samples and 21 sets of matched lung ADC primary foci and metastatic foci from the Department of Pathology at Tianjin Medical University
Cancer Institute and Hospital from January 2014 to December 2014. None of the patients had received any chemotherapy or radiotherapy before their operation. All the samples underwent a uniform protocol for fixation/ dissection and processing schedule. All sections were evaluated by two senior pathologists. The use of the tissue samples in this study was approved by the Institutional Research Committee.

\section{Immunohistochemical staining}

The paraffin-embedded sections were deparaffinized by sequential washing with xylene, graded ethanol and PBS. Endogenous peroxidase activity was blocked with $0.3 \% \mathrm{H}_{2} \mathrm{O}_{2}$ for $30 \mathrm{~min}$ before antigen retrieval by microwave treatment in citrate phosphate buffer. The sections were incubated overnight at $4{ }^{\circ} \mathrm{C}$ with rabbit anti-FGF4, rabbit anti-Orai1, rabbit anti-E-cadherin, rabbit anti-Vimentin and mouse anti-Ki-67 diluted in PBS (FGF4 1:50, Orai1 1:50, E-cadherin: 1:50, Vimentin: 1:50, Ki-67: 1:100). As a control, sections were stained with the biotinylated anti-rabbit only. After being washed three times with PBS, the sections were incubated with appropriate secondary antibodies for $1 \mathrm{~h}$ at room temperature. The processed sections were examined using an Olympus BX51 microscope images were captured using the AnalySIS program.

The expression of FGF4, E-cadherin, Vimentin, and Orail was analyzed only histologically in neoplastic epithelial cells. FGF4 and Orail staining was considered immunoreactive when brown granules were identified in the cytoplasm. The staining intensity of FGF4 and Orai1 was graded on a scale from 0 to 2 ( 0 for no staining, 1 for weak immunoreactivity, 2 for strong immunoreactivity). Percentage immunoreactivity was scored on a scale from 0 to 3 ( 0 for no positive cells, 1 for $<25 \%$ of cells being positive, 2 for $25 \%$ to $50 \%$ of cells being positive, and 3 for $>50 \%$ of cells being positive). The two scores were multiplied to obtain a composite expression score. The final expression level was classified as negative (-) $($ score $=0$,$) , weakly positive (+)($ score $=1,2$, or 3$)$, or strongly positive $(++)($ score $=4,5$, or 6$)$. E-cadherin expression was considered to be positive if $>90 \%$ of tumor cells exhibited a staining pattern similar to that in normal epithelial cells. Vimentin expression was classified as positive when $>10 \%$ tumor cells were stained. Ki-67 expression was considered to be positive if $>30 \%$ of tumor cells with brown stained nucleus.

\section{Statistical analysis}

SPSS v.16.0 software (SPSS Inc., Chicago, IL, USA) was used for data analysis. Data are expressed through at least triplicate independent determinations. Data were presented as means \pm SD. The associations between FGF4 and clinicopathologic parameters and 
the differential expression of E-cadherin, Vimentin and Orail between different FGF4 expression level groups were assessed with Fisher's exact test and chi-square test. Differences between groups were assessed by the MannWhitney U-test and the Student's t-test. Two-tailed values of $P<0.05$ were considered statistically significant.

\section{ACKNOWLEDGMENTS}

This study was supported by the Project of the Natural Science Foundation of China (grants no. 81402420 and no. 81001186), the Project of Tianjin Natural Science Foundation (grants no. 15JCQNJC12400 and no. 13JCYBJC21800), the Project of Tianjin Municipal Health Bureau (grant no. 2015KZ082), and the National Key Clinical Specialist Construction Programs of China (grant no.2013-544).

\section{CONFLICTS OF INTEREST}

No conflicts of interest to declare.

\section{Author contributions}

Study concept and design: Wenfeng Cao, Bin Zhang, Lisha Qi; Acquisition of data: Wangzhao Song, Lingmei Li, Lu Cao, Yalei Wang, Chunming Song; Analysis and interpretation of data: Yue Yu, Fei Zhang; Drafting of the manuscript: Lisha Qi, Wangzhao Song and Wenfeng Cao.

\section{REFERENCES}

1. Flippot R, Kone M, Magne N, Vignot S. [FGF/FGFR signalling: Implication in oncogenesis and perspectives]. [Article in French]. Bull Cancer. 2015; doi: 10.1016/j .bulcan.2015.04.010.

2. Katoh M, Nakagama H. FGF receptors: cancer biology and therapeutics. Med Res Rev. 2014; 34: 280-300. doi: 10.1002/med.21288.

3. Parish A, Schwaederle M, Daniels G, Piccioni D, Fanta P, Schwab R, Shimabukuro K, Parker BA, Helsten T, Kurzrock R. Fibroblast growth factor family aberrations in cancers: clinical and molecular characteristics. Cell Cycle. 2015; 14: 2121-8. doi: 10.1080/15384101.2015.1041691.

4. Donnem T, Al-Shibli K, Al-Saad S, Busund LT, Bremnes RM. Prognostic impact of fibroblast growth factor 2 in nonsmall cell lung cancer: coexpression with VEGFR-3 and PDGF-B predicts poor survival. J Thorac Oncol. 2009; 4: 578-85. doi: 10.1097/JTO.0b013e31819f2e38.

5. Creighton CJ, Gibbons DL, Kurie JM. The role of epithelial-mesenchymal transition programming in invasion and metastasis: a clinical perspective. Cancer Manag Res. 2013; 5: 187-95. doi: 10.2147/CMAR.S35171.

6. Davis FM, Azimi I, Faville RA, Peters AA, Jalink K, Putney JW, Jr., Goodhill GJ, Thompson EW, Roberts-Thomson SJ, Monteith GR. Induction of epithelial-mesenchymal transition
(EMT) in breast cancer cells is calcium signal dependent. Oncogene. 2014; 33: 2307-16. doi: 10.1038/onc.2013.187.

7. Savagner P, Valles AM, Jouanneau J, Yamada KM, Thiery JP. Alternative splicing in fibroblast growth factor receptor 2 is associated with induced epithelial-mesenchymal transition in rat bladder carcinoma cells. Mol Biol Cell. 1994; 5: 851-62.

8. Hu Y, Mintz A, Shah SR, Quinones-Hinojosa A, Hsu W. The FGFR/MEK/ERK/brachyury pathway is critical for chordoma cell growth and survival. Carcinogenesis. 2014; 35: 1491-9. doi: 10.1093/carcin/bgu014.

9. Abolhassani A, Riazi GH, Azizi E, Amanpour S, Muhammadnejad S, Haddadi M, Zekri A, Shirkoohi R. FGF10: Type III Epithelial Mesenchymal Transition and Invasion in Breast Cancer Cell Lines. J Cancer. 2014; 5: 537-47. doi: 10.7150/jca.7797.

10. Liu R, Huang S, Lei Y, Zhang T, Wang K, Liu B, Nice EC, Xiang R, Xie K, Li J, Huang C. FGF8 promotes colorectal cancer growth and metastasis by activating YAP1. Oncotarget. 2015; 6: 935-52. doi: 10.18632/ oncotarget.2822.

11. Suzuki T, Yasuda H, Funaishi K, Arai D, Ishioka K, Ohgino K, Tani T, Hamamoto J, Ohashi A, Naoki K, Betsuyaku T, Soejima K. Multiple roles of extracellular fibroblast growth factors in lung cancer cells. Int J Oncol. 2015; 46: 423-9. doi: 10.3892/ijo.2014.2718.

12. Li J, Wei Z, Li H, Dang Q, Zhang Z, Wang L, Gao W, Zhang P, Yang D, Liu J, Sun Y, Gao W. Clinicopathological significance of fibroblast growth factor 1 in non-small cell lung cancer. Hum Pathol. 2015; 46: 1821-8. doi: 10.1016/j .humpath.2015.07.022.

13. Ohgino K, Soejima K, Yasuda H, Hayashi Y, Hamamoto J, Naoki K, Arai D, Ishioka K, Sato T, Terai H, Ikemura S, Yoda S, Tani T, et al. Expression of fibroblast growth factor 9 is associated with poor prognosis in patients with resected non-small cell lung cancer. Lung Cancer. 2014; 83: 90-6. doi: 10.1016/j.lungcan.2013.10.016.

14. Guo M, Liu W, Serra S, Asa SL, Ezzat S. FGFr2 isoforms support epithelial-stromal interactions in thyroid cancer progression. Cancer Res. 2012; 72: 2017-27. doi: 10.1158/0008-5472.CAN-11-3985.

15. Nomura S, Yoshitomi H, Takano S, Shida T, Kobayashi S, Ohtsuka M, Kimura F, Shimizu H, Yoshidome H, Kato A, Miyazaki M. FGF10/FGFR2 signal induces cell migration and invasion in pancreatic cancer. Br J Cancer. 2008; 99: 305-13. doi: 10.1038/sj.bjc.6604473.

16. Yan G, Fukabori Y, McBride G, Nikolaropolous S, McKeehan WL. Exon switching and activation of stromal and embryonic fibroblast growth factor (FGF)-FGF receptor genes in prostate epithelial cells accompany stromal independence and malignancy. Mol Cell Biol. 1993; 13: 4513-22.

17. Fearon AE, Gould CR, Grose RP. FGFR signalling in women's cancers. Int J Biochem Cell Biol. 2013; 45: 2832 42. doi: 10.1016/j.biocel.2013.09.017. 
18. Zhang X, Zhou Z, Wang D, Li A, Yin Y, Gu X, Ding F, Zhen X, Zhou J. Activation of phosphatidylinositol-linked D1-like receptor modulates FGF-2 expression in astrocytes via IP3-dependent Ca2+ signaling. J Neurosci. 2009; 29: 7766-75. doi: 10.1523/JNEUROSCI.0389-09.2009.

19. Chen YF, Chen YT, Chiu WT, Shen MR. Remodeling of calcium signaling in tumor progression. J Biomed Sci. 2013; 20: 23. doi: 10.1186/1423-0127-20-23.

20. Bergamaschi A, Kim YH, Kwei KA, La Choi Y, Bocanegra M, Langerod A, Han W, Noh DY, Huntsman DG, Jeffrey SS, Borresen-Dale AL, Pollack JR. CAMK1D amplification implicated in epithelial-mesenchymal transition in basallike breast cancer. Mol Oncol. 2008; 2: 327-39. doi: 10.1016/j.molonc.2008.09.004.

21. Davis FM, Kenny PA, Soo ET, van Denderen BJ, Thompson EW, Cabot PJ, Parat MO, Roberts-Thomson SJ, Monteith GR. Remodeling of purinergic receptormediated $\mathrm{Ca} 2+$ signaling as a consequence of EGFinduced epithelial-mesenchymal transition in breast cancer cells. PLoS One. 2011; 6: e23464. doi: 10.1371/journal .pone.0023464.

22. Davis FM, Parsonage MT, Cabot PJ, Parat MO, Thompson EW, Roberts-Thomson SJ, Monteith GR. Assessment of gene expression of intracellular calcium channels, pumps and exchangers with epidermal growth factorinduced epithelial-mesenchymal transition in a breast cancer cell line. Cancer Cell Int. 2013; 13: 76. doi: 10.1186/1475-2867-13-76.

23. Mertens-Walker I, Bolitho C, Baxter RC, Marsh DJ. Gonadotropin-induced ovarian cancer cell migration and proliferation require extracellular signal-regulated kinase $1 / 2$ activation regulated by calcium and protein kinase C\{delta\}. Endocr Relat Cancer. 2010; 17: 335-49. doi: 10.1677/ERC-09-0152.

24. Lin KL, Chi CC, Lu T, Tseng LL, Wang JL, Lu YC, Jan CR. Effect of sertraline on $[\mathrm{Ca} 2+](\mathrm{i})$ and viability of human MG63 osteosarcoma cells. Drug Chem Toxicol. 2013; 36: 231-40. doi: 10.3109/01480545.2012.710625.

25. Clemens RA, Lowell CA. Store-operated calcium signaling in neutrophils. J Leukoc Biol. 2015; 98: 497-502. doi: 10.1189/jlb.2MR1114-573R.

26. Xie J, Pan H, Yao J, Zhou Y, Han W. SOCE and cancer: Recent progress and new perspectives. Int J Cancer. 2015. doi: 10.1002/ijc.29840.

27. Hu J, Qin K, Zhang Y, Gong J, Li N, Lv D, Xiang R, Tan $\mathrm{X}$. Downregulation of transcription factor Oct4 induces an epithelial-to-mesenchymal transition via enhancement of $\mathrm{Ca} 2+$ influx in breast cancer cells. Biochem Biophys Res Commun. 2011; 411: 786-91. doi: 10.1016/j .bbrc.2011.07.025.

28. Marek L, Ware KE, Fritzsche A, Hercule P, Helton WR, Smith JE, McDermott LA, Coldren CD, Nemenoff RA, Merrick DT, Helfrich BA, Bunn PA, Jr., Heasley LE. Fibroblast growth factor (FGF) and FGF receptormediated autocrine signaling in non-small-cell lung cancer cells. Mol Pharmacol. 2009; 75: 196-207. doi: 10.1124/ mol.108.049544.

29. Nguyen PT, Tsunematsu T, Yanagisawa S, Kudo Y, Miyauchi M, Kamata N, Takata T. The FGFR1 inhibitor PD173074 induces mesenchymal-epithelial transition through the transcription factor AP-1. Br J Cancer. 2013; 109: 2248-58. doi: 10.1038/bjc.2013.550.

30. Yamayoshi T, Nagayasu T, Matsumoto K, Abo T, Hishikawa Y, Koji T. Expression of keratinocyte growth factor/ fibroblast growth factor-7 and its receptor in human lung cancer: correlation with tumour proliferative activity and patient prognosis. J Pathol. 2004; 204: 110-8. doi: 10.1002/ path.1617.

31. Oltean S, Sorg BS, Albrecht T, Bonano VI, Brazas RM, Dewhirst MW, Garcia-Blanco MA. Alternative inclusion of fibroblast growth factor receptor 2 exon IIIc in Dunning prostate tumors reveals unexpected epithelial mesenchymal plasticity. Proc Natl Acad Sci U S A. 2006; 103: 14116-21. doi: 10.1073/pnas.0603090103.

32. Yasuda K, Torigoe $\mathrm{T}$, Mariya $\mathrm{T}$, Asano $\mathrm{T}$, Kuroda $\mathrm{T}$, Matsuzaki J, Ikeda K, Yamauchi M, Emori M, Asanuma H, Hasegawa T, Saito T, Hirohashi Y, et al. Fibroblasts induce expression of FGF4 in ovarian cancer stem-like cells/ cancer-initiating cells and upregulate their tumor initiation capacity. Lab Invest. 2014; 94: 1355-69. doi: 10.1038/ labinvest.2014.122.

33. Siddiqi I, Funatomi H, Kobrin MS, Friess H, Buchler MW, Korc M. Increased expression of keratinocyte growth factor in human pancreatic cancer. Biochem Biophys Res Commun. 1995; 215: 309-15. doi: 10.1006/bbrc.1995.2467.

34. Abell AN, Granger DA, Johnson NL, Vincent-Jordan N, Dibble CF, Johnson GL. Trophoblast stem cell maintenance by fibroblast growth factor 4 requires MEKK4 activation of Jun N-terminal kinase. Mol Cell Biol. 2009; 29: 2748-61. doi: 10.1128/MCB.01391-08.

35. Didiasova M, Zakrzewicz D, Magdolen V, Nagaraj C, Balint Z, Rohde M, Preissner KT, Wygrecka M. STIM1/ORAI1mediated Ca2+ Influx Regulates Enolase-1 Exteriorization. J Biol Chem. 2015; 290: 11983-99. doi: 10.1074/jbc .M114.598425.

36. Zuccolo E, Bottino C, Diofano F, Poletto V, Codazzi AC, Mannarino S, Campanelli R, Fois G, Marseglia GL, Guerra G, Montagna D, Laforenza U, Rosti V, et al. Constitutive store-operated $\mathrm{Ca} 2+$ entry leads to enhanced nitric oxide production and proliferation in infantile hemangiomaderived endothelial colony forming cells. Stem Cells Dev. 2015. doi: 10.1089/scd.2015.0240.

37. Chen YF, Chiu WT, Chen YT, Lin PY, Huang HJ, Chou CY, Chang HC, Tang MJ, Shen MR. Calcium store sensor stromal-interaction molecule 1-dependent signaling plays an important role in cervical cancer growth, migration, and angiogenesis. Proc Natl Acad Sci U S A. 2011; 108: 15225 30. doi: 10.1073/pnas.1103315108.

38. Niu J, Chang Z, Peng B, Xia Q, Lu W, Huang P, Tsao MS, Chiao PJ. Keratinocyte growth factor/fibroblast growth 
factor-7-regulated cell migration and invasion through activation of NF-kappaB transcription factors. J Biol Chem. 2007; 282: 6001-11. doi: 10.1074/jbc.M606878200.

39. Kook SH, Jeon YM, Lim SS, Jang MJ, Cho ES, Lee SY, Choi KC, Kim JG, Lee JC. Fibroblast growth factor-4 enhances proliferation of mouse embryonic stem cells via activation of c-Jun signaling. PLoS One. 2013; 8: e71641. doi: 10.1371/journal.pone.0071641.

40. Davis FM, Peters AA, Grice DM, Cabot PJ, Parat MO, Roberts-Thomson SJ, Monteith GR. Non-stimulated, agonist-stimulated and store-operated $\mathrm{Ca} 2+$ influx in MDA-MB-468 breast cancer cells and the effect of EGFinduced EMT on calcium entry. PLoS One. 2012; 7: e36923. doi: 10.1371/journal.pone.0036923.
41. Xu Y, Zhang S, Niu H, Ye Y, Hu F, Chen S, Li X, Luo X, Jiang S, Liu Y, Chen Y, Li J, Xiang R, et al. STIM1 accelerates cell senescence in a remodeled microenvironment but enhances the epithelial-tomesenchymal transition in prostate cancer. Sci Rep. 2015; 5: 11754. doi: 10.1038/srep11754.

42. Casas-Rua V, Tomas-Martin P, Lopez-Guerrero AM, Alvarez IS, Pozo-Guisado E, Martin-Romero FJ. STIM1 phosphorylation triggered by epidermal growth factor mediates cell migration. Biochim Biophys Acta. 2015; 1853: 233-43. doi: 10.1016/j.bbamcr.2014.10.027. 